Original article

\title{
Male gender is an important clinical risk factor for iron deficiency in healthy infants
}

\author{
Henedina Antunes ${ }^{\mathrm{a}, \mathrm{b}, *}$, Cristina Santos $^{\mathrm{c}}$, Susana Carvalho ${ }^{\mathrm{a}}$, Sónia Gonçalves ${ }^{\mathrm{d}}$, Altamiro Costa-Pereira ${ }^{\mathrm{c}}$ \\ ${ }^{a}$ Gastroenterology, Hepatology and Nutrition Unit, Pediatric Department, Hospital de Braga Sete Fontes - S. Victor Apartado 2056, 4701-901 Braga, Portugal \\ ${ }^{\mathrm{b}}$ Life and Health Sciences Research Institute (ICVS), School of Health Sciences, University of Minho, Campus de Gualtar, 4709-057 Braga, ICVS/3B's, PT Government Associate \\ Laboratory, Braga/Guimarães, Portugal \\ ${ }^{c}$ Department of Biostatistics and Medical Informatics, Faculty of Medicine, Porto University, Porto, Portugal \\ ${ }^{\mathrm{d}}$ Department of Psychology, University of Minho, Braga, Portugal
}

\section{A R T I C L E I N F O}

\section{Article history:}

Received 12 January 2009

Accepted 13 September 2012

\section{Keywords:}

Iron deficiency

Gender

Infants

Risk profile

Iron deficiency anaemia

\begin{abstract}
S U M M A R Y
Background $\mathcal{E}$ aims: To identify ID risk factors in infancy, and try to explore why ID is more prevalent in boys than in girls in the first year of life.

Methods: A multiple logistic regression was performed on data of $201 \mathrm{infants}$, with ferritin $<12 \mathrm{ng} / \mathrm{ml}$ as the dependent variable and months of breastfeeding, weight gain from birth to 9 months (WG), and gender as independent variables. To compare haematological parameters we used Mann-Whitney and $t$ test.

Results: From the 39 infants with IDA (19.4\%), 24 (61.5\%) were male and of the 162 infants without IDA, $50 \%$ were male ( $p=0.195)$. The median(minimum; maximum) ferritin concentrations in male infants at 9 months was of $9.8 \mathrm{ng} / \mathrm{ml}(0.5-67.0 \mathrm{ng} / \mathrm{ml})$ and in females $14 \mathrm{ng} / \mathrm{ml}(0.5-74.5 \mathrm{ng} / \mathrm{ml}), p<0.001$. The average $( \pm$ SD) WG was of $5863.3 \mathrm{~g}( \pm 855.4 \mathrm{~g})$ in male infants and $5556.9 \mathrm{~g}( \pm 1054.3 \mathrm{~g})$ in female infants $(p=0.027)$.

A multiple logistic regression (OR; $95 \% \mathrm{CI}$ ) showed that male gender was the most important risk factor (OR: $3.3 ; 1.7-6.3 ; p<0.001$ ), followed by a higher weight increase (OR: $1.6 ; \mathrm{CI}[1.1 ; 2.2] ; p=0.016)$ and longer breastfeeding time (OR: $1.1 ; \mathrm{CI}[0.98 ; 1.2] ; p=0.099$ ).

Comparison of other haematological parameters at 9 months in relation to gender (males (M): 105; females (F): 96) showed significant differences in: mean \pm SD, Mean Corpuscular Haemoglobin (M: $25.0 \pm 2.1 ; \mathrm{F}: 25.8 \pm 2.4 \mathrm{pg}, p=0.001)$, Mean Corpuscular Volume (M: $73.4 \pm 4.1 ; \mathrm{F}: 75.3 \pm 4.2 \mathrm{fl}, 0.009)$, RDW (M: $14.6 \pm 1.5 ; \mathrm{F}: 14.1 \pm 1.6 \%, p=0.048$ ), Plaquelets (M: $324.9 \pm 77.9 ; \mathrm{F}: 350.5 \pm 81.4 \times 10^{3} / \mu \mathrm{l}$, $p=0.026)$.

Conclusions: ID was significantly more frequent in male infants, independent of rapid growth or longer breastfeeding duration.

The clinical risk profile for ID in infants includes male gender and not only rapid growth, and longer breastfeeding duration.

(c) 2012 Published by Elsevier Ltd on behalf of European Society for Clinical Nutrition and Metabolism.
\end{abstract}

\section{Introduction}

Iron requirements in humans vary according to age and gender. ${ }^{1}$ The iron deficient anaemia (IDA) criteria depend on the following factors: age, gender, altitude, and eventual pregnancy. ${ }^{2}$ At present, the consensus is to separate the IDA criteria by gender starting only at puberty. ${ }^{3}$ Using the current definitions, there is a male predominance in infants with IDA and therefore, it should be asked

\footnotetext{
* Corresponding author. Gastroenterology, Hepatology and Nutrition Unit, Pediatric Department, Hospital de Braga Sete Fontes - S. Victor Apartado 2056, 4701-901 Braga, Portugal. Tel.: +351 253027000; fax: +351 253027999.

E-mail address: henedinaantunes@gmail.com (H. Antunes).
}

whether the IDA definition in infants should be differentiated by gender at an earlier age. ${ }^{4}$ In fact, if in puberty the endocrine changes provide an explanation for different IDA criteria, there is no clear reason for this incongruity in infancy. Domellof et al. proposed to change the IDA criteria in infants by gender. ${ }^{4}$ However, it can be argued that it is not the criteria that should be changed but the iron requirements in the first year of life. ${ }^{5}$ Actually, if there is a greater body weight increase in male infants in the first year of life and if male infants have more lean body mass than girls, ${ }^{6}$ these factors could explain the ID predominance in male infants. ${ }^{5}$

Lozoff et al. tried to find variables associated with ID and reported that a greater rapid growth was associated with an increased incidence of ID in infants. ${ }^{6}$ 
In 2007, Wieringa et al., published a study using a large database from four randomized controlled trials and showed that infant boys had 3.3 times higher risk of suffering from ID than girls. Wieringa et al. concluded that the iron requirements in first year of life need to be differentiated by gender, based on the response to iron supplementation. ${ }^{7}$ Longer breastfeeding period $^{8,9}$ and faster growth are positively correlated with ID risk. ${ }^{6}$

Genetic and/or hormonal factors may be responsible for weight and lean body mass differences and perhaps these differences can be related to either iron status or more probably increased iron requirements in the first year of life in males.

Is faster growth in males the only reason for the reported gender differentiation pertaining to ID in infants, or are there other factors also involved, namely different iron genetic profile?

The aim of this study is to identify risk factors for ID in infancy, and try to explore why ID is more prevalent in boys than in girls in the first year of life.

\section{Participants and methods}

All newborns from Braga Hospital (BH), a Portuguese University and tertiary Hospital, born between 30 August and 3 October 1994 with the following criteria were included: healthy term newborn with adequate weight for gestational age ${ }^{10}$ and being a single birth. The entire group was observed at the age of nine months.

\subsection{Protocol of the study at nine months}

The protocol of the study included: mothers' complete clinical information (age, income, education, number of previous births, and iron supplementation during pregnancy), the child newborn and infant - feeding (number of months of breastfeeding, formula feeding, age at introduction of solid food), vaccination (national programme or/and other vaccines not included in it), supplements (vitamins or minerals), anthropometrical data (weight, length, and head circumference at birth and at nine months), and family social-economic and cultural information. The same paediatrician assembled the protocol information through hospital records, personal health registers, parents query and physical examination.

Infants' blood samples were taken for complete blood cell count and for serum iron, transferrin, and ferritin. The blood samples were collected in test tubes with EDTA (Niro-Neotube ${ }^{\circledR}$ ). All samples were analysed between $30 \mathrm{~min}$ and $2 \mathrm{~h}$ after collection, in the automatic counting blood cell system of Sysmex Toa-Medical Electronics Co., Kobe ${ }^{\circledR}$. Smears were done in all who presented anaemia or any other cellular indices alterations. Serum iron concentration was measured by the "Ferrozyne" method (Hoffman La Roche ${ }^{\circledR}$ ) and transferrin concentrations by the turbo-diametric method (Dako, CobasMiras-Roche Diagnostics ${ }^{\circledR}$ ). Ferritin was determined by the radio-immunoassay (Diagnostic Products Corporation ${ }^{\circledR}$ ), the method of determination that has been considered standard since $1985 .^{11}$

\subsection{IDA and ID definition}

The IDA definition used was from the WHO: in 9 month old infants haemoglobin $(\mathrm{Hb})<110 \mathrm{~g} / \mathrm{l}^{12}$ with low ferritin. The ID definition used was ferritin $<12 \mathrm{ng} / \mathrm{ml}^{12}$

\subsection{Study design}

This is an observational study with iron therapy in infants with IDA according to WHO diagnostic criteria at 9 months of age.
Infants with IDA completed the treatment with oral iron supplements, in the form of iron sulphate solution, $3 \mathrm{mg} / \mathrm{kg} / \mathrm{day}$, twice daily and before meals.

All IDA infants needed to have treatment with oral iron supplements for at least four months and to a maximum of six.

\subsection{Statistical analysis}

A multivariate analysis was applied with a cut off of $12 \mathrm{ng} / \mathrm{ml}$ of ferritin as a dependent variable at 9 months. For independent variables, we used breastfeeding duration, gender and weight gain from birth to the age of nine months. To compare haematological parameters we used Mann-Whitney $U$ and $t$ test.

\subsection{Ethics}

Written consent was obtained from the children's parents involved in this research.

The Ethical Committee of SMH approved this study.

\section{Results}

From the newborns selected at birth, 54 were excluded for not fulfilling the basal criteria: 35 being larger for their gestational age; 7 had intra-uterine growth retardation (IUGR); 8 were premature and 4 were born from multiple births.

At 9 months of age, 246 infants were called. From these, 15 (6\% of the eligible sample) did not come to the appointment and 5 infants were excluded for not meeting the inclusion criteria ( 3 were larger for their gestational age, 1 IUGR and 1 premature) and, erroneously, had been included in the sample.

From these 226, 25 infants did not complete the protocol (11\% was the total sample loss after observation). The parents of 23 infants refused the blood sample collection and in 2 the blood sample was insufficient. Hence, of the 246 newborns selected, 201 infants completed the entire protocol (83.4\%).

There were no statistical differences between the mothers (age, social environment, number of years of education, number of previous births, and iron supplementation during pregnancy) and newborns (weight, length, and head circumference at birth), in the group studied and in the group excluded from analysis due to not completing the protocol.

The $\mathrm{Hb}$ was less than $110 \mathrm{~g} / \mathrm{l}$ in 83 (41.3\%) out of 201 infants; the prevalence of ID was 39.3\% (79 infants) [95\%CI, 32.5-46.2\%].

Within infants with IDA, $17(43.6 \%)$ had $\mathrm{Hb}$ concentrations between 109 and $105 \mathrm{~g} / \mathrm{l} ; 14$ (35.9\%) between 104 and $100 \mathrm{~g} / \mathrm{l}$, and the remaining 8 (20.5\%) infants had $\mathrm{Hb}$ concentrations between 99 and $90 \mathrm{~g} / \mathrm{l}$. The lowest value of $\mathrm{Hb}$ found in this 9 month old population was $91 \mathrm{~g} / \mathrm{l}$. Of the infants with anaemia but without IDA, $34.0 \%$ had $\mathrm{Hb}$ of $109 \mathrm{~g} / \mathrm{l}$.

The prevalence of IDA was $19.4 \%$ (39 infants), [95\%CI; $14.5-$ $25.4 \%]$.

All 39 infants with IDA initiated oral iron treatment, $3 \mathrm{mg} / \mathrm{kg} /$ day, which they maintained until $\mathrm{Hb}$ values as well as ferritin levels had normalized. After 3 months of therapy, three of these infants (7.7\%) did not present $\mathrm{Hb}$ levels equal or superior to $110 \mathrm{~g} / \mathrm{l}$, but there was a increase of the $\mathrm{Hb}>10 \mathrm{~g} / \mathrm{l} ; 23$ infants (59.0\%) had ferritin concentrations $<12 \mu \mathrm{g} / \mathrm{l}$. At the sixth month mark of therapy on oral iron, all 39 infants with IDA normalized both the $\mathrm{Hb}$ and ferritin levels.

The average breastfeeding duration was 3 months (range: $0-9$ months) in males and 3 months (1-9 months) in females $(p=0.737)$. The number of months on iron supplemented formula was 4 months (0-9 months) in males and 4 months (0-9 months) in females $(p=0.732)$. 
The haematological parameters at 9 months by gender are shown in Table 1.

Of the 39 infants suffering from IDA, 24 (61.5\%) were male and of the 162 infants without IDA, $50 \%$ were male $(p=0.195)$.

Ferritin concentrations were significantly lower in male infants than in female infants at 9 months of age. The median ferritin concentration in male infants was of $9.8 \mathrm{ng} / \mathrm{ml}$ (range: $0.5-67.0 \mathrm{ng} /$ $\mathrm{ml}$ ) and in females it was of $14.0 \mathrm{ng} / \mathrm{ml}$ (range $0.5-74.5 \mathrm{ng} / \mathrm{ml}$ ), $p<0.001$. Of a total of 105 male infants, 55 had low ferritin levels at nine months, and 24 out of the 96 female infants had low ferritin levels $(p<0.001)$.

Twenty-four out of the 55 males fulfilled the criteria of IDA. Fifteen out of the 24 females had IDA ( $p=0.195$ ).

The mean $( \pm \mathrm{SD})$ weight gain between birth and nine months was $5863.3 \mathrm{~g}(855.4 \mathrm{~g})$ in male infants and $5556.9 \mathrm{~g}(1054.3 \mathrm{~g})$ in female infants $(p=0.027)$.

In the multivariate analysis (Table 2 ) for weight, the risk for ID increased 1.6 times for each $1 \mathrm{~kg}$ increase in weight $(p=0.016)$. Furthermore, every additional month of breastfeeding increased the risk for ID 1.1 times $(p=0.099)$. However, regardless of the weight gain and breastfeeding duration, males had an increased risk of 3.3 times of having ID in infancy than girls $(p<0.001)$ showing that males are faced with an increased risk of having ID after correcting for weight gain and breastfeeding duration.

\section{Discussion}

This study shows that male infants have an increased risk for ID, which is not explained by differences in weight gain or breastfeeding practices.

Why is there a higher prevalence of boys rather than girls suffering from ID in the first year of life? There are very few previous studies addressing this question. ${ }^{4}$

The higher proportion of male children in studies on IDA in infants $^{4,5,13}$ is quite constant, with few exceptions. ${ }^{6}$ In our study, ferritin concentrations in male infants were also significantly lower than in females at 9 months of age.

Sherriff et al. ${ }^{14}$ also found, in 1141 children studied in the United Kingdom, that ferritin concentrations at twelve months were lower in males. However, there is not a definite and consensual answer among the scientific community that this predominance of males with ID may be explained by physiological, genetic, and/or endocrine differences between the sexes. One explanation for the high risk for ID in male infants could be the gain of more muscle mass in boys or simply that the higher increase of body weight makes them more vulnerable to ID.

Table 1

Haematological parameters at 9 months by gender.

\begin{tabular}{|c|c|c|c|c|c|}
\hline \multirow[b]{2}{*}{ At 9 months } & \multicolumn{2}{|c|}{ Males $(n=105)$} & \multicolumn{2}{|c|}{ Females $(n=96)$} & \multirow[b]{2}{*}{$p^{*}$} \\
\hline & Mean & SD & Mean & SD & \\
\hline Haemoglobin $(\mathrm{g} / \mathrm{l})$ & 112.3 & 6.0 & 111.7 & 9.6 & 0.614 \\
\hline Haematocrit (\%) & 33.2 & 2.4 & 33.0 & 2.6 & 0.540 \\
\hline Mean corp. haemogl. (pg) & 25.0 & 2.1 & 25.8 & 2.4 & 0.001 \\
\hline Mean corp. volume (fl) & 73.4 & 4.1 & 75.3 & 4.2 & 0.009 \\
\hline $\mathrm{MCHC}(\mathrm{g} / \mathrm{dl})$ & 34 & $31-36$ & 34 & $31-36$ & $0.064^{* *}$ \\
\hline Platelets $\left(\times 10^{3} / \mu \mathrm{l}\right)$ & 324.9 & 77.9 & 350.5 & 81.4 & 0.026 \\
\hline RDW (\%) & 14.6 & 1.5 & 14.1 & 1.6 & 0.048 \\
\hline Leucocytes $\left(\times 10^{3} / \mu \mathrm{l}\right)$ & 9.08 & 2.60 & 9.38 & 3.2 & 0.208 \\
\hline Transferrin (mg/dl) & 279.3 & 56.1 & 266.8 & 54.9 & 0.113 \\
\hline Ferritin (ng/ml) & 9.8 & $0.5-67$ & 14.0 & $0.5-74$ & $<0.001^{* *}$ \\
\hline Iron (ng/dl) & 44.4 & 21.8 & 39.7 & 20.2 & 0.118 \\
\hline
\end{tabular}

SD: standard-deviation. ${ }^{*}$ test $t{ }^{* *}$ test Mann-Whitney $U$.

$\mathrm{m}$ - minimum; M - maximum; MCHC: mean corpuscular haemoglobin concentration.
Table 2

Multivariate analyses with ferritin at 9 months as dependent variable (less than $12 \mathrm{ng} / \mathrm{ml}$ ) and independently variables: months of breastfeeding, weight gain from birth to 9 months, in $\mathrm{kg}$, and gender.

\begin{tabular}{llll}
\hline Risk of iron deficiency at nine months & OR & $95 \% \mathrm{CI}$ & $p$ \\
\hline Weight gain (in kg) & 1.6 & {$[1.1 ; 2.2]$} & 0.016 \\
Months of breastfeeding & 1.1 & {$[0.98 ; 1.2]$} & 0.099 \\
Gender & & & \\
$\quad$ Female & - & & \\
$\quad$ Male & 3.3 & {$[1.7 ; 6.3]$} & $<0.001$ \\
\hline OR = odds ratio; $\mathrm{Cl}=$ Confidence interval; Iron deficiency = ferritin less than $12 \mathrm{ng} / \mathrm{ml}$.
\end{tabular}

In Wieringa et al.'s study in Southeast Asia, the risk of ID in boys was 3.3 times higher than in girls. ${ }^{7}$ The study used four databases including a large sample for an iron interventional study from three different Southeast Asian countries. ${ }^{7}$ Although it was totally different from ours, which used a small prospective Portuguese sample of infants to study neurodevelopmental differences between IDA and non-IDA infants, ${ }^{5}$ the results in both studies were similar: higher risk for ID in male infants.

Domellof et al. proposed a definition of ID differences between the sexes in the first year of life due to male predominance of ID. ${ }^{4}$ This observation could be linked to the irons' kinetics in the first year of life, or it could reflect the dietary influence and the probable lean body mass increase, which is demonstrated in Motil et al.'s chart $^{15}$ : a gain of $4.0 \mathrm{~kg}$ of lean mass in females during the first year versus $4.8 \mathrm{~kg}$ in males or merely a higher weight increment in boys, knowing that weight gain implies more iron needs. ${ }^{6}$ Genetic factors may also be responsible for explaining this increased ID risk profile but also could explain the weight gain and higher probability of lean body mass.

Can the weight gain be the only reason for the increased prevalence of boys in studies on IDA in infancy? In our research, we showed that there was a significant weight gain difference when comparing the two sexes, with males gaining more weight. ${ }^{5}$ As the highest weight increment is associated with a higher iron requirement, the risk of ID and IDA ${ }^{6,8,9}$ in boys could be naturally justified. The largest weight increment and lean body mass difference between the sexes could be genetically determined, but the final result is a higher requirement for iron in the first year of life in males. However, although the weight gain increment was positively associated to ID risk, the multivariate analysis showed that the male gender is more susceptible to ID, even when correcting for differences in weight gain. Hence, weight gain did not explain all the increased risk for boys having ID in infancy.

In our study, being a male is a far greater risk factor for low ferritin concentrations than rapid growth ${ }^{6}$ or longer breast feeding. ${ }^{8,9}$

If the differences found were only the result of the kinetics of iron in the first year of life, and due to this, the definition of ID should be modified in this age group, this would not explain why these infants that were studied, predominantly males, had worse results in the Griffiths test at twelve, fifteen months and five years. ${ }^{5}$ The Griffiths test is a development test with a general coefficient and five sub-scales that measures the development of the child and can be used until eight years of age. ${ }^{16}$ The existence of repercussions in infants' development sustains the hypothesis of functional ID, and not that of a definition of ID or IDA by gender, in this age group. Wieringa's study confirms the hypothesis because in iron supplemented boys this difference between the levels of ferritin by gender was not found; it only existed in non-supplemented infants. $^{7}$

Male gender is a clinical risk factor for ID in infants and it is well known that IDA in infants is associated with development delay. ${ }^{5}$ 
The iron supplement is not innocuous and the blood test for IDA in all infants is difficult to obtain and a clinical risk profile is needed. As a clinical risk profile we propose male gender, weight gain from birth to six months and breastfeeding duration. In our study, at the age of nine months, some of the infants were already suffering from IDA or ID $^{5}$ which implied development delay. Thus, perhaps that risk profile should be applied at the age of six months.

The iron requirements in the first year of life must be revaluated and perhaps altered according to gender, concluding that the difference in body weight gain cannot explain all these differences in gender.

Recently, a study tracked $\mathrm{Hb}$ from 6 months of life to 4 years old and the results showed no influence of food except significantly high ferritin in boys who consumed meat. ${ }^{17}$ These results were in line with ours and give more arguments to a genetic profile.

There are five meta-analysis published in medline about oral iron therapy before 18 years, but none only in infants or in developed countries. ${ }^{7,9,18-20}$

We invite other researchers to study ID in the first year of life to use their databases to contest or confirm these results.

\section{Authors' contribution}

Henedina Antunes - Conception and design of the study acquisition of data, analysis and interpretation of data and wrote the article.

Cristina Santos - reviewed the statistical analysis.

Susana Carvalho - introduction of patients' data in the database.

Sónia Gonçalves - performed Griffiths test.

Altamiro Costa-Pereira - Conception and design of the study and reviewed the statistical analysis.

All authors read and approved the final manuscript.

\section{Conflict of interest}

None declared.

\section{Acknowledgements}

To the children and families who were involved in this study.

To BH Pathology Clinic Dpt.

This study received a scholarship from the Foment Commission for Investigation in Health Care, from the Health Ministry P.I. n ${ }^{\circ}$ 87/07.

\section{References}

1. Foods and Nutrition Board, Institute of Medicine. Iron. In: Dietary reference intakes for vitamin $A$, vitamin $K$, arsenic, boron, chromium, copper, iodine iron, manganese, molybdenum, nickel, silicon, vanadium, and zinc; 2002. p. 290-393.

2. Baker SJ, DeMaeyer EM. Nutritional anaemia: its understanding and contro with special reference to the work of the World Health Organization. Am J Clin Nutr 1979;32:368-417.

3. World Health Organisation (WHO). Technical Report, series $n^{\circ} 405$. Nutritional anaemia's: WHO Scientific Group report, Geneva; 1968.

4. Domellof M, Lonnerdal B, Dewey KG, Cohen RJ, Rivera LL, Hernell O. Sex differences in iron status during infancy. Pediatrics 2002;110:545-52.

5. Antunes H, Gonçalves S, Teixeira-Pinto A, Costa-Pereira A, Tojo-Sierra R, Aguiar A. Iron-deficiency anemia in infants - preliminary development results at five years. Acta Med Port 2005;18:261-6.

6. Lozoff B, Kaciroti N, Walter T. Iron deficiency in infancy: applying a physiologic framework for prediction. Am J Clin Nutr 2006;84(6):1412-21.

7. Wieringa FT, Berger J, Dijkhuizen MA, Hidayat A, Ninh NX, Utomo B, et al. Sex differences in prevalence of anaemia and iron deficiency in infancy in a large multi-country trial in south-east Asia. Br J Nutr 2007;31:1-7.

8. WHO. Diet, nutrition and the prevention of chronic diseases report of a joint WHO/FAO expert consultation. WHO technical report services 916. Geneva; 2003.

9. Baker R, Greer F, The Committee on Nutrition. Clinical report diagnosis and prevention of iron deficiency and iron-deficiency anemia in infants and young children (0-3 years of age). Pediatrics 2010;126:1040-50.

10. Lubchenco LO, Hansman C, Boyd E. Intrauterine growth in length and head circumference as estimated from live births at gestational ages from 26 to 42 weeks. Pediatrics 1966;37:403-8.

11. International Committee for Standardization in Haematology (Expert panel on iron). Proposed international standard of human ferritin for serum ferritin assay. Br J Haemat 1985;61:61-3.

12. Gibson RS. Principles of nutritional assessment. Oxford: Oxford University Press; 1990.

13. Ziegler E, Nelson S, Jeter J. Iron supplementation of breastfed infants from an early age. Am J Clin Nutr 2009;89:525.

14. Sherriff A, Emond A, Hawkins N, Golding J, the ASPAC Children in Focus Study Team. Haemoglobin and ferritin concentrations in children aged 12 and 18 months. Arch Dis Child 1999;80:153-7.

15. Motil KJ, Philips SM, Conkin CA. Nutritional assessment. In: Wyllie R, Hyams JS editors. Pediatric gastrointestinal disease. Philadelphia: WB Saunders Company; 1999. p. $717-40$.

16. Griffiths R. The abilities of young children. A comprehensive system of mental measurement for the first eight years of life. London, UK: Child Development Research Center; 1970.

17. Ohlund I, Lind T, Hörnell A, Hernell O. Predictors of iron status in wellnourished 4-y-old children. Am J Clin Nutr 2008;87(4):839-45

18. Falkingham M, Abdelhamid A, Curtis P, Fairweather-Tait S, Dye L, Hooper L. The effects of oral iron supplementation on cognition in older children and adults: a systematic review and meta-analysis. Nutr J 2010;9(4):1-16.

19. Iannotti LL, Tielsch JM, Black MM, Black RE. Iron supplementation in early childhood: health benefits and risks. Am J Clin Nutr 2006;84(6):1261-76.

20. Sachdev H, Gera T, Nestel P. Effect of iron supplementation on physical growth in children: systematic review of randomised controlled trials. Public Health Nutr 2006;9(7):904-20. 